biomes, particularly during the Pleistocene.

The final chapter, on marine ecology, is rather sketchy and superficial. It gives the impression of being an afterthought.

In my opinion there are three major weaknesses in this book when it is considered as a possible undergraduate text. The first is its lack of information concerning plants. This is particularly noticeable and unfortunate in the chapters on habitat, where it would have completed an otherwise detailed and interesting series of accounts. Although this omission is confessed frankly in the sub-title, it nevertheless reduces the usefulness of the book as an ecological teaching tool. The second weakness from the point of view of British ecologists is its almost exclusive use of North American examples. This must limit severely its value and its sales potential outside the United States and Canada. The third way in which the book could have been improved is by the inclusion of more physiological information about the animals considered. I cannot agree with the author's statement in the Preface that such information is only of value at advanced levels of training.

Despite these reservations I found the style, content and production of this book attractive and interesting.

Peter D. Moore

\section{What is biological control?}

Biological Control of Plant Pathogens. By K. F. Baker, and R. J. Cook. Pp. xiv +433 . (Freeman: San Francisco, 1974.) $\$ 12.50$.

THE authors of this book admit that writing it was a "mind-stretching" exercise; many readers may think that the effort has somewhat distended their subject. The dilemma faced by the authors was how far to extend beyond the difficulty of defining 'biological control' into the wider problems of managing microbial ecology to lessen plant diseases. Early usage of the term fitted well into S. D. Garrett's statement (in Pathogenic root-infecting fungi, Cambridge University Press 1970) that biological control is "mediated by one or more organisms (excepting man himself) outside the host-parasite relationship". On page 43 of this book the authors arrive at their much broader and wordier concept: "Biological control is the reduction of inoculum density or diseaseproducing activities of a pathogen or parasite in its active or dormant state by one or more organisms, accomplished naturally or through manipulation of the environment, host or antagonist, or by mass introduction of one or more antagonists."

This concept is so broad that it embraces all of microbial ecology and much of agriculture, except the use of chemicals aimed solely against pathogens. It is of course commendable that plant pathologists should consider all the factors affecting the biology of plant pathogens but, despite the inevitable demarcation disputes, many would share my preference to restrict the term 'biological control' to the manipulation of 'third organisms' such as hyperparasites, antagonists and competitors. A more comprehensive term would be needed to comprise the important natural environmental and artificial factors which are

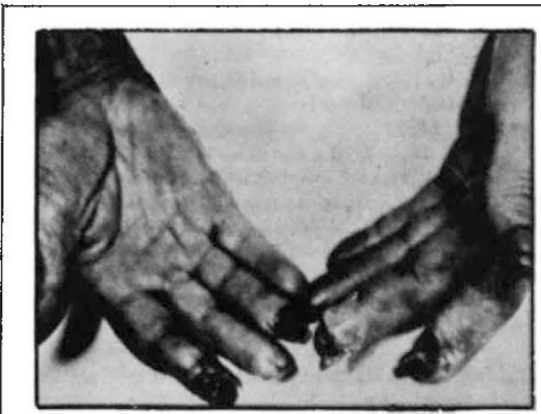

The hands of a workman who had been operating a pneumatic drill for 26 years. The prolonged vibration caused stiffness swelling and. finally, dry gangrene in the fingers. From The Vibration Syndrome. Edited by W. Taylor. Pp. xii +226 . (Academic Press: London, August 1974.) £6.00; $\$ 15.50$.

included as biological in this book; for example, tillage, choice of planting date, and organic and inorganic additives (including fertilisers). In Chapter 9 the authors come perilously close to accepting chemotherapeutants as another factor, thus removing the chief objection to adopting the well established term 'integrated control'.

The first two chapters contain a somewhat unhappy blend of unnecessarily elementary introduction, good sense, and an emotional attitude to unbalanced 'environmentalist' arguments. Both authors have, however, enviable reputations as root pathologists and most of the book comprises a skilled and up to date compilation of knowledge concerning root pathogens. It is comforting to see one chapter devoted to pathogens of aerial parts: but that occupies a mere 20 of the 350 pages of text and so can be no more than an apology to satisfy the completeness that the title suggests. In their preface the authors disclaim comprehensiveness and admit that they have often put a personal interpretation on results which is different from that of the authors they quote. That this is a risky procedure is reinforced by several authors who claim to have been misrepresented, which breeds doubts about inaccuracies elsewhere.

Inevitably, much of the evidence from the literature is anecdotal and biased, because successes are more often reported than failures (which may be more frequent). With a few notable exceptions it is therefore very difficult to obtain balanced estimates of the value to agriculture of modifications to microbial ecology or control by 'third organisms'. Experience with the decline phenomenon in take-all disease of cereals (Gaumannomyces graminis) suggests that the variability between cropping histories, soils and fields is so great that it will be long before we can confidently predict the effects of antagonists or of developments in biological buffering. These are not, however, reasons for criticising a book that collects together much scattered information, presents it systematically for the first time, and contains more than the usual amount of constructive thinking.

Plainly, the authors did not want this to be an ordinary book; it is not. It will periodically delight, interest and infuriate its readers; but these seem to be characteristics of the books that prove most formative to their subjects and I think time will show this book to be important.

J. M. Hirst

\section{Of mites and models}

The Functional Response to Prey Density in an Acarine System. (Simulation Monographs.) By H. G. Fransz. Pp. viii + 143. (Centre for Agricultural Publishing and Documentation: Wageningen, 1974.) Dff. 20.

DURING the last few years ecological theory seems to have outpaced the collection of ecological data. Professor Maynard Smith's book Models in Ecology (Cambridge University Press, 1974) showed amply that models can be formulated and built, but that their testing on real data and validation by prediction in the real world is still not possible because of a shortage of data. It was with these thoughts in mind that I welcomed Fransz's book which describes systems whereby the mite Typhlodromus occidentalis preys on various stages of another mite Tetranychus urticae. The book combines the observational approach to this predatorprey system with model building and validation by comparison with experimental results.

The first two chapters provide an introduction to the experimental system and the variables that the author measured (prey density, hunger, locomotion velocity and so on), and the third chapter describes the results of 